\title{
Píxeles de piedra. Visibilidad y ocultación en el oppidum de San Cibrán de Las (Ourense)
}

\author{
Stone pixels. Visibility and concealment in the oppidum of San Cibrán de Las (Ourense)
}

\author{
Pastor Fábrega-Álvarez
}

\begin{abstract}
RESUMEN
Este trabajo discute la simulación como estrategia de análisis espacial en Arqueología. A partir del uso combinado de tecnologías geoespaciales, se propone el estudio, a gran escala, de la estructura visual de un sitio arqueológico. La propuesta se desarrolla en el oppidum de San Cibrán de Las (Ourense), en donde se analiza la permeabilidad visual de su estructura en el paisaje. La metodología desarrollada usa distintos recursos para entender cómo la construcción del poblado pudo condicionar la percepción visual desde dentro y desde fuera. Mediante la manipulación de un modelo digital del terreno (MDT) se construyen distintos escenarios que son analizados a partir de cálculos sistemáticos de visibilidad. Los resultados se orientan a la interpretación de la visibilidad y ocultación de la acción social en los distintos espacios del poblado durante la Edad del Hierro.
\end{abstract}

\begin{abstract}
This paper discusses simulation as a strategy for spatial analysis in archeology. We propose a large-scale study of the visual structure of an archaeological site based on the combined use of different geospatial technologies. The methodology is developed in the oppidum of San Cibrán de Las (Ourense, Spain), where the visual permeability of its structure in the landscape is analyzed. The methodology we develop uses different digital simulation resources to understand how the construction of different archaeological structures could condition visual perception. Different scenarios were constructed changing a digital terrain model (DTM), which was analyzed based on viewshed calculations. The results are oriented to the interpretation of the visibility and concealment of social action in the different spaces of hillfort during the Iron Age.
\end{abstract}

Palabras clave: Arqueología del Paisaje; Visibilidad; Edad del Hierro; NO de la península ibérica; Simulación Espacial; Tecnologías de Información Geográfica; Sistemas de Información Geográfica; LiDAR; Fotogrametría.

Key words: Landscape Archeology; Visibility; Iron Age; NW of the Iberian peninsula; Spatial Simulation; Geographical Information Technologies; Geographic Information Systems; LiDAR; Photogrammetry.

\section{INTRODUCCIÓN}

La simulación como estrategia computacional es un procedimiento ampliamente conocido en disciplinas como la Física. En Arqueología su uso no está extendido, aunque es conocido desde los años 70 (e. g. Hodder 1978; Sabloff 1981). Su aplicación no se reduce a un ámbito arqueológico, habiendo sido más relevante en campos como la evolución humana (Lake 2014: 277-278). Aunque existen distintos tipos de simulación, en los últimos años han destacado los 1lamados ABM - agent based model-(Wurzer et al. 2015) basados en modelos construidos por agentes que interaccionan entre sí dentro de un entorno en el que se lleva a cabo experimentos virtuales (Gilbert 2008: 2). A diferencia de otras aproximaciones a la simulación, los ABM permiten trabajar con sistemas sociales virtuales (e.g. Barceló 2012), por lo que están teniendo cierto éxito en ciencias sociales, y más específicamente en Arqueología.

Según R. E. Shannon y J. Johannes (1976) la simulación es el proceso de diseñar un modelo de un

a Instituto de Ciencias del Patrimonio (Incipit). Consejo Superior de Investigaciones Científicas (CSIC). Avda. de Vigo s/n. 15705 Santiago de Compostela. A Coruña. Correo e.: pastor.fabrega-alvarez@incipit.csic.es http://orcid.org/0000-0001-5371-438X

Recibido 17-VII-2020; aceptado 2-IX-2020.

Copyright: (C) 2020 CSIC. Este es un artículo de acceso abierto distribuido bajo los términos de la licencia de uso y distribución "Creative Commons Reconocimiento 4.0 Internacional" (CC BY 4.0) 
sistema real y llevar a término experiencias con él con el fin de comprender el comportamiento del sistema. En el mismo sentido, Ariza et al. (2001) se refieren a la simulación espacial como un estudio del comportamiento del sistema real a partir de la observación del modelo digital (e. g. Fábrega-Álvarez 2004: 14). Así la simulación vendría definida por el simple uso de un modelo digital con el objetivo de analizar un fenómeno. Esa definición permitiría considerar como simulación espacial casi cualquier metodología desarrollada con Sistemas de Información Geográfica (SIG) para analizar un fenómeno arqueológico. Por ejemplo, los llamados modelos predictivos han sido utilizados, desde hace décadas, para modelizar condiciones locacionales de un conjunto de yacimientos con el fin de detectar otros con condiciones locacionales análogas o de analizar su variabilidad locacional en una zona determinada (e. g. Brandt et al. 1992; Stancic y Veljanovski 2000; Hatzinikolaou et al. 2003). Más específicamente, contamos con algunos desarrollos que se ajustarían más a un uso más consciente y paradigmático de simulación espacial en Arqueología, y que han recurrido a software-SIG para integrar variables geográficas (e. g. Zubrow 1997; Lake 2000; Branting et al. 2007).

Por tanto, el uso del concepto de simulación espacial puede ser confuso. Para el propósito que nos ocupa hablar de simulación espacial como estrategia de análisis requiere la construcción de un modelo digital, la alteración de una de sus propiedades y la valoración de esa alteración. Por ejemplo, el uso de un modelo 3D de un recipiente para analizar sus huellas de uso no sería simulación. En cambio, lo sería si alteráramos su forma para analizar su desgaste con el uso y estudiáramos esas variaciones. El ejemplo nos sirve también para ilustrar que nuestra propuesta parte de la capacidad de las tecnologías geoespaciales para manipular y alterar las dimensiones de un modelo. En adelante, utilizaremos esta definición de simulación, no para negar cualquier otra, sino para evitar confusiones sobre la estrategia que proponemos.

A pesar del éxito en las dos últimas décadas de los SIG en el marco de la arqueología del paisaje, su uso, como herramienta de análisis, no ha sido dirigido hacia estrategias de simulación espacial. La gran mayoría de los trabajos se han orientado hacia el análisis de patrones locacionales de sitios arqueológicos, caracterizados a partir de variables derivadas de modelos digitales del terreno (MDT) como la accesibilidad, la movilidad o la visibilidad (e. g. Gillings et al. 1999; Lock 2000; en España e. g. Grau 2006; Mayoral y Celestino 2011; Mayoral et al. 2017). Sin embargo estos trabajos parten de un modelo del terreno que hace referencia a una única realidad, o bien al terreno actual, o en casos excepcionales a modelos que tratan de reproducir el terreno prístino, normalemente eliminando las huellas digitales de infraestructuras recientes en la topografía. En un caso o en otro, los análisis no se han dirigido a valorar el cambio que produce la alteración del terreno, sino a justificar que el modelo es válido para analizar el contexto de estudio.

Desde el marco de la arqueología del paisaje, la simulación puede ser una estrategia orientada a estudiar cómo los cambios de la materialidad pueden modificar aspectos como la movilidad o la percepción. Las Tecnologías de Información Geográfica (TIG) nos ayudan a entender mejor estos cambios relacionados con la espacialidad de los sitios arqueológicos en el paisaje. La obtención de MDT de alta resolución ha sido posible gracias a la introducción de tecnologías digitales como el LiDAR (Light Detection and Ranging o Laser Imaging Detection and Ranging) o la fotogrametría, ambas potenciadas con el desarrollo y la generalización de los vehículos aéreos no tripulados (VANT). Además, las nuevas políticas ${ }^{1}$ de producción y distribución de información geográfica proporcionan datos masivos a gran escala con coberturas cada vez más amplias. Los SIG, nutridos de estos modelos, ofrecen una capacidad de análisis que abren nuevas posibilidades para entender los restos arqueológicos en el paisaje. Si en las dos últimas décadas los SIG fueron orientados para entender la localización de los sitios arqueológicos, ahora tenemos la posibilidad de analizar cómo la arquitectura condiciona la visibilidad o el acceso de un sitio arqueológico en el paisaje. Estamos en disposición de abordar una nueva escala de integración espacial de las estructuras arqueológicas en los modelos digitales. Obviamente el camino no está exento de problemas, tal y como veremos.

La potencialidad de la simulación espacial en Arqueología radica, en primer lugar, en la posibilidad de evaluar un sistema real ausente (pasado) a partir de un modelo reconstruido. En segundo lugar, comprender las implicaciones de un elemento material en el paisaje, al margen de la intencionalidad de su concepción, exigiría analizarlo más allá de lo que es (en su estado actual) y de lo que fue (en su estado original). Para una comprensión aun mayor, necesitaríamos analizar lo que pudo haber sido. Es decir, alterar ese elemento fuera del alcance que ha tenido, por ejemplo, situándolo en otro lugar o alterando su forma y tamaño. En este sentido, la simulación en arqueología del paisaje abre un abanico de posibilidades que deben ser exploradas, ya que supone una mayor comprensión de cómo la materialidad modifica la percepción o el movimiento del ser humano.

\footnotetext{
${ }^{1}$ La directiva INSPIRE (https://inspire.ec.europa.eu/inspire-directive/2) de la UE es un buen ejemplo de estas políticas que han mejorado la producción y el acceso a cualquier información de carácter geográfico.
} 
La fragmentación es una de las características que definen el registro arqueológico. La representación del pasado parte de una materialidad incompleta y alterada. Esta pérdida constituye un problema para definir con precisión la forma y el tamaño original de cualquier elemento arqueológico. A menudo es posible abordar la recuperación de esa información. Por ejemplo, a partir del volumen de derrumbe es posible aproximarse a la altura original de un muro. Si bien debemos reconocer que las condiciones de conservación en muchos casos suponen pérdida de información. Por tanto, la simulación en Arqueología debe lidiar continuamente con cierta imprecisión, tal y como veremos en el caso de estudio, que supone lo que hemos llamado incertidumbre. Conviene, pues, diseñar la estrategia de análisis para que esta incertidumbre no suponga una enmienda a la totalidad de los resultados. Dicha incertidumbre no solamente viene dada por la conservación de la materialidad o su estado de conocimiento, sino también por la calidad del modelo digital. En este sentido, debemos diseñar estrategias para valorar la imprecisión. Además, conviene establecer ciertos límites en la interpretación bajo los que se contengan estos niveles de incertidumbre.

Estas ideas se desarrollan a continuación en un caso de estudio concreto localizado en el oppidum de San Cibrán de Las (Ourense), en donde se valora la permeabilidad visual de los distintos espacios. Para ello se exploran distintos recursos relacionados con la simulación espacial. El primero consiste en variar la altura actual de las murallas, y el segundo en bloquear la visibilidad a partir de las murallas para analizar la permeabilidad visual a partir de las puertas y las calles. Los resultados se discuten en relación a la incertidumbre sobre la altura original de las murallas en el contexto de la Edad del Hierro. Parte del trabajo fue desarrollado en el marco de mi tesis doctoral (Fábrega-Álvarez 2017).

\section{CASO DE ESTUDIO. EL OPPIDUM DE SAN CIBRÁN DE LAS (OURENSE)}

El oppidum de San Cibrán (Punxín-San Amaro, Ourense) es un poblado fortificado de la Edad del Hierro del noroeste de la península ibérica (Anexo AC3), objeto de investigación en varias campañas de excavación (e. g. López 1925; Chamoso 1954; Pérez 1987; Fariña y Fernández 1989; López et al. 2004; Álvarez 2009). Podemos considerar el yacimiento como uno de los primeros centros urbanos del noroeste peninsular. La monumentalidad de sus murallas y su gran extensión (10 ha) lo han convertido en un referente para el estudio de las sociedades del final de la Edad del Hierro y la primera época indígena-romana en Galicia.
San Cibrán presenta una arquitectura pétrea y se configura en dos recintos principales concéntricos, cada uno de ellos rodeado por una muralla (Fig. 1). El primero (R1 en adelante), situado en la parte más alta ("croa" en gallego) y sin evidencias de estructuras habitacionales, ha sido interpretado como un espacio de uso comunitario, simbólico y ritual (Bernardo y García-Quintela 2008; Álvarez et al. 2009; GarcíaQuintela et al. 2014; Álvarez et al. 2017a, 2017b), argumento que descansa, entre otras evidencias (Álvarez et al. 2009), en la existencia de inscripciones dedicadas a deidades locales o restos de prácticas rituales ancestrales y anteriores a la construcción del poblado (Álvarez et al. 2017a, 2017b). El segundo recinto (R2 en adelante) tiene una gran densidad de estructuras habitacionales complejas, que incluyen viviendas, graneros y patios. La movilidad en este recinto se organiza a partir de dos rondas: una superior, aneja y concéntrica a la muralla que forma la "croa" por su parte exterior; y otra inferior, aneja y concéntrica a la muralla principal por su parte interior. Ambas rondas están conectadas a partir de calles principales que unen los accesos de las puertas, y calles secundarias. Esta estructura parece haberse concebido ya a partir de un diseño previo, materializado en una primera fase en el siglo II a. C. (Álvarez et al. 2009: 195).

Los trabajos de excavación y conservación se han centrado, a grandes rasgos, en tres zonas donde se ha intervenido con distinta intensidad: zonas excavadas y consolidadas donde se observa el suelo prístino de ocupación, así como las distintas rondas y elementos arquitectónicos (construcciones domésticas, calzadas, aljibes, etc.); zonas no excavadas de pradera o monte bajo; y zonas de arbolado y matorral denso casi sin acceso ni visibilidad. Mención aparte merecen los trabajos en las murallas que estructuran los recintos del poblado. En algunos tramos han sido excavadas y consolidadas (sector O-S-E) y, en otros, están soterradas y cubiertas de vegetación (sector N). En definitiva, el estado del sitio arqueológico permite valorar integralmente San Cibrán y su entorno desde el punto de vista perceptivo, pero la precisión de las valoraciones debe ajustarse a cada zona y a su estado de conocimiento. En general, el eje E-O del poblado pertenece a esa primera zona, ampliamente excavada, consolidada y bien conocida. Además, el estado de cada una de ellas se refleja en el modelo digital del terreno utilizado para realizar los cálculos de visibilidad, que reproduce mejor la morfología original del poblado precisamente en ese eje E-O.

A continuación, analizamos cómo esta estructuración arquitectónica dialoga con la topografía en el paisaje, configurando el acceso a distintos espacios y su percepción a partir de las murallas. Dichos espacios, pautan la comunicación visual en el interior del po- 

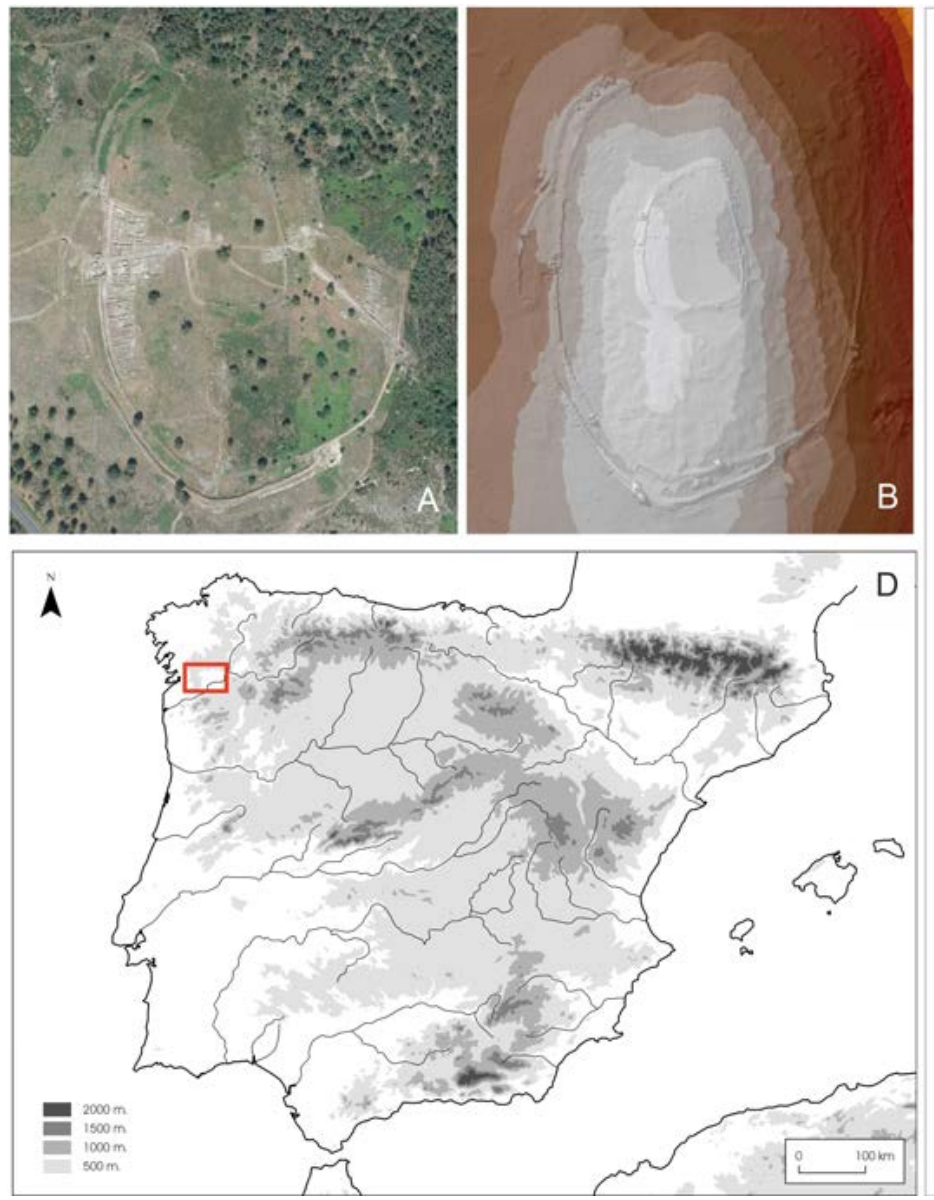
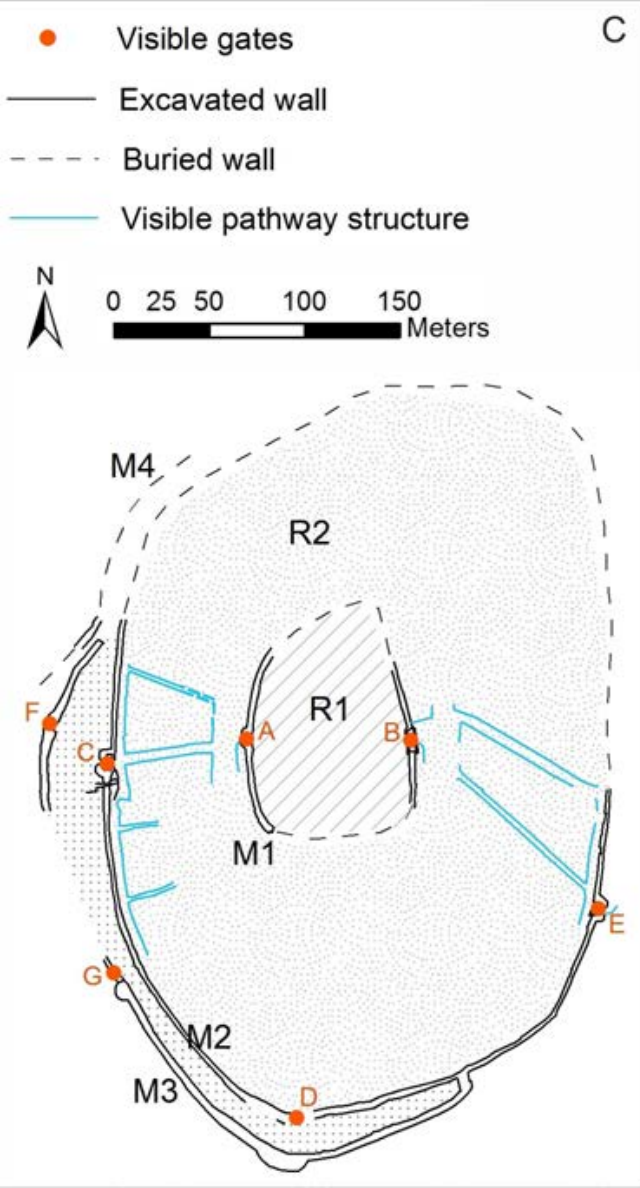

Fig. 1. Localización (D) y estructura del oppidum de San Cibrán de Las (C), formado por la "croa" (R1) y el recinto habitacional (R2), con superficies próximas a 1 y 8 ha respectivamente. Ortofotografía del PNOA (A). MDT de 0,5 m de resolución, obtenido a partir de la nube de puntos LiDAR del PNOA y representado a intervalos de altitud cada $5 \mathrm{~m}$ (B). En color en la edición electrónica.

blado, hacia su entorno o desde el entorno hacia el poblado. El análisis nos abre una puerta a pensar cómo los poblados fortificados de la Edad del Hierro modificaron y restringieron el acceso y la percepción, no solamente en sus espacios interiores, sino también desde ellos hacia su entorno.

\section{PLANTEAMIENTOS: VISIBILIDAD, REPRESENTACIÓN E INCERTIDUMBRE}

F. Criado-Boado (2012: 265-292) define cuatro estrategias de visibilidad para los distintos segmentos del registro arqueológico: monumentalidad, exhibición, inhibición y ocultación. Estas estrategias asociadas a la materialidad arqueológica, no implican que la visibilidad responda a una intención consciente, sino a una circunstancia intrínseca, racional y no empírica de los procesos sociales (Criado-Boado
2012: 273). La asociación unívoca de un elemento arqueológico a una de estas estrategias puede ser excesivamente simplificadora, oscureciendo la riqueza de matices que puede darse en una misma situación. En este trabajo exploraremos esta afirmación en San Cibrán, un espacio donde en un mismo contexto se da un entramado de estrategias de visibilidad definidas por la interacción entre espacios (recintos y entornos) y estructuras (murallas): exhibiendo, inhibiendo, monumentalizando u ocultando la materialidad y prácticas sociales asociadas a ellas. Lo que es mas relevante aún es que esas prácticas se restringen visualmente a ciertos espacios cuyo acceso está, como veremos, manifiestamente pautado.

Como en muchos otros sitios arqueológicos, las murallas de San Cibrán no conservan su alzado original. En la actualidad, a pesar de mantener cierta altura (Fig. 2 y Anexo Tab. A), la percepción visual es, en general, muy abierta entre los distintos recintos, 


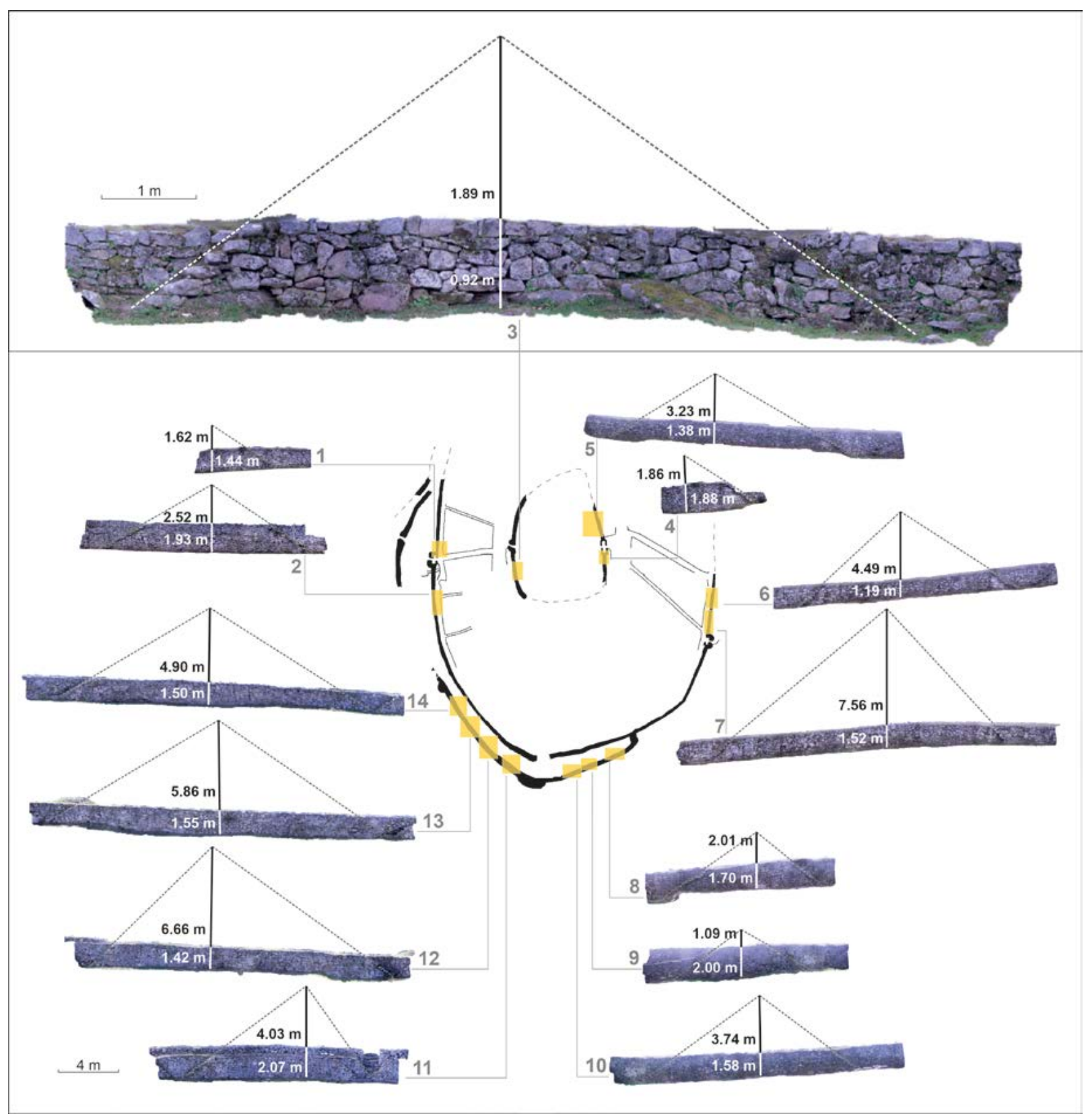

Fig. 2. Estimación de la altura máxima de la muralla del oppidum de San Cibrán de Las, basada en la proyección de sus escaleras interiores. En la figura se representan la altura conservada (en blanco) y la altura desde lo alto de la muralla al punto de intersección de las rectas proyectadas a partir de la pendiente de las escaleras (en negro). La proyección fue calculada a partir de las ortofotos que aparecen en la figura. Las ortofotos fueron obtenidas a partir de pares fotográficos, utilizando dianas georreferenciadas con un GPS geodésico, y procesadas con el software Agisoft Metashape. En color en la edición electrónica.

tanto desde el entorno hacia el sitio como a la inversa. A mayor altura puede que la percepción entre los distintos recintos se acotara mucho más. A pesar de la dificultad que entraña, es posible aproximarse a la altura original de la muralla. El volumen de los derrum- bes o la proyección de sus elementos constructivos son indicadores de su altura original. En este sentido es posible hacer una primera valoración de la altura máxima de la muralla a partir de la proyección de las escaleras de acceso. Estas escaleras, situadas al interior, 
son numerosas y conservan los arranques formados por un número variable de peldaños. Su construcción fue concebida en muchos casos a partir de pares en donde las escalares son enfrentadas y tendentes, geométricamente, a encontrarse a una altura determinada. Esa altura puede ser interpretada como la altura máxima que podría alcanzar la muralla, ya que si se cruzaran las escaleras perderían funcionalidad como estructura de acceso al paseo de ronda (Álvarez 2020). Otros elementos con función de parapetos, como empalizadas o almenas, podrían alcanzar cotas superiores respecto a esa altura máxima que marca, en realidad, la altura del paseo de ronda en la parte superior de la muralla. En la figura 2 se muestra esta estimación de altura máxima y su distribución en diferentes tramos de las murallas. La tendencia central de altura máxima es mayor en las murallas de acceso al poblado que en la que rodea el recinto interior (Anexo Tab. A). Las magnitudes de esta primera estimación no se alejan de las realizadas por sus excavadores a partir de otros indicadores. F. López Cuevillas calculaba una altura de $3 \mathrm{~m}$ para la muralla que rodea la "croa" (M1), según el cómputo de sus derrumbes (Álvarez 2020: 417). Y. Álvarez (2020: 421) afirma, a partir de la información recabada en las últimas campañas de excavación, que las murallas exteriores (M2, M3) podrían alcanzar 4 o $5 \mathrm{~m}$ de altura, teniendo en cuenta que la muralla tendría 2,5 o $3 \mathrm{~m}$ a los que habría añadir $2 \mathrm{~m}$ más por existencia de un adarve.

La estrategia que proponemos a continuación, aunque tiene en cuenta estas estimaciones, maneja la incertidumbre de la altura de la muralla como parte del planteamiento metodológico. Así pues, valoramos la propia existencia de la muralla, en la medida en la que ésta alteró perceptivamente el paisaje, tal vez incluso más allá de la voluntad para la que fue concebida. Por tanto, proponemos el análisis de distintos modelos topográficos en donde la altura en toda la superficie que ocupan las murallas ha sido alterada para construir cinco escenarios: en el primero la muralla es desmantelada por completo (unwalled), en el segundo presenta su altura actual (present walls) y los restantes suman a esta altura 75, 150 y $300 \mathrm{~cm}$. El criterio para establecer los distintos escenarios está determinado por una combinación entre la precisión del modelo topográfico, los cálculos de visibilidad y las estimaciones de la altura máxima que pudo alcanzar la muralla.

El modelo digital del terreno sobre el que pivota nuestro análisis fue elaborado a partir de datos LiDAR del Plan Nacional de Ortofotografía Aérea (PNOA) del Instituto Geográfico Nacional (IGN). El procesamiento a partir de distintos algoritmos permite discriminar la información topográfica del terreno de la masa vegetal. Combinando diferentes técnicas (véase ANEXO) fue posible elaborar un modelo que maximiza la can- tidad de puntos que representan el volumen de las murallas, lo cual es imprescindible en la medida que, espacialmente, dicho elemento limita las posibilidades perceptivas de los recintos del oppidum. El resultado fue un modelo digital del terreno (MDT) de $50 \mathrm{~cm}$ de resolución que representa tanto el poblado como su entorno de hasta $2 \mathrm{~km}$ (Anexo AC1). La calidad del MDT ha sido valorada a partir de un test de visibilidad en campo, que compara los resultados de respuesta entre modelo y sistema real (Anexo AC2). Los resultados fueron satisfactorios y se detallan en el Anexo. La muralla en toda su extensión fue delimitada en planta para, a partir de esta, definirla en altura configurando distintos MDT que referencian los distintos escenarios comentados en el párrafo anterior (unwalled, present walls, $+75,+150 \mathrm{y}+300 \mathrm{~cm})$. Conviene señalar que la anchura de la muralla se ajusta a la planta original en aquellos sectores en los que la muralla ha sido excavada (sector E-N-O), mientras se extiende en planta a la totalidad del derrumbe en aquellos sectores en la que no es visible y permanece soterrada (sector N). Como decíamos, en estos sectores la valoración tiene en cuenta estas imprecisiones.

En definitiva, nos proponemos comprender mejor las implicaciones perceptivas que tuvo la construcción de las murallas en San Cibrán a partir de los escenarios posibles que hemos planteado, e independientemente de la altura concreta que alcanzara la muralla. Nuestra intención ha sido evaluar las implicaciones del amurallamiento más allá de su función originaria de impedir el paso. En este sentido, el planteamiento no está lejos de concebir la materialidad, en este caso la muralla, como agente, en un sentido disociado de la intencionalidad (Malafouris 2008). Como dice Latour (2005: 226): there might exist many metaphysical shades between full causality and sheer nonexistence [in terms of agency]: things might authorise, allow, afford, encourage, permit, suggest, influence, block, render possible, forbid and so on. Con este planteamiento es posible entender mejor algunas posibilidades que relacionan la agencia de la muralla en términos de accesibilidad y percepción visual. Aunque como decíamos, nos hemos centrado en analizar la muralla como barrera visual desde el interior (ocultación del entorno) y exterior (ocultación) del poblado. Las estrategias de visibilidad de los distintos elementos en San Cibrán interaccionan entre sí monumentalizando, exhibiendo, ocultando o inhibiendo de forma concatenada esos distintos espacios y elementos arquitectónicos que componen el poblado. Cuando la muralla se levanta y se proyecta como monumento, las viviendas y estructuras interiores se ocultan, al menos desde el exterior del oppidum. Esta articulación es compleja en San Cibrán debido a la existencia de distintos recintos amurallados, cuyos espacios parecen presentar diferencias

Trab. Prehist., 77, N. ${ }^{\circ}$ 2, julio-diciembre 2020, pp. 303-319, ISSN: 0082-5638

https://doi.org/10.3989/tp.2020.12258 
significativas en su función y sentido. En los apartados siguientes intentaremos desenredar algo más este juego.

\section{ESTRATEGIA DE CÁlCULO Y RESULTADOS}

El estudio de la visibilidad ha sido planteado a partir de una estrategia de muestreo, dado que el modelo del terreno (MDT) es muy pesado para un software (ArcGIS 10.4) que no está optimizado para utilizar todo el potencial de los procesadores actuales. Hemos utilizado una malla regular de puntos que representan visores situados a $170 \mathrm{~cm}$ por encima del terreno, emulando la altura de un individuo. La densidad de la malla es de $5 \mathrm{~m}$ en los recintos interiores del poblado (R1 y R2), de $25 \mathrm{~m}$ en el entorno inmediato (500 m desde la muralla exterior), y de $100 \mathrm{~m}$ en un entorno más alejado (hasta $2000 \mathrm{~m}$ ). Con esta estrategia, a partir de una rutina automatizada se han generado más de 100.000 cálculos de visibilidad (viewshed). Para facilitar su comprensión, las figuras muestran el porcentaje de superficie visible de cada recinto desde cada visor de la malla. En general, consideramos "residual" la visibilidad inferior al $3 \%$ del espacio. Frecuentemente corresponde bien a pequeños errores del modelo, bien a visibilidades puntuales sin la continuidad suficiente para percibir con claridad la acción social que se desarrollaría con cierta extensión en un cierto espacio. Las visibilidades de los espacios superiores a ese $3 \%$ las hemos denominado "efectivas". Para facilitar su lectura, en algunas figuras solo hemos reflejado la visibilidad efectiva, indicándolo en la leyenda de la imagen.

De esta forma podemos analizar en qué medida visibilizamos desde la localización de cada recinto al otro. Quedan así definidos tres espacios que son analizados de dos maneras complementarias: la posible visibilidad desde ellos de otros espacios y, a la inversa, en qué medida ellos son visibles desde esos espacios. Los espacios manejados están definidos topológicamente por las murallas y son esencialmente el recinto superior o "croa" (R1), el recinto habitacional (R2) y el entorno del poblado (E). Este último a veces se analiza hasta $2000 \mathrm{~m}$ (E2000), aunque en otros casos haremos referencia a distancias más próximas como 50 (50E), 100 (100E), 150 (150E), 200 (E200) o $500 \mathrm{~m}$ (E500). Esta triple definición no es aleatoria sino que responde a la voluntad de acotarlos y separarlos mediante una muralla ya en una primera fase de construcción del poblado. En este sentido, y a pesar de que el recinto habitacional (R2) estaría ocupado en gran parte por construcciones y patios techados, no hemos reducido los cálculos a espacios abiertos como rondas y calles. La razón principal es que pretendemos una valoración de la estructura de San Cibrán en relación con su diseño de configuración del espacio basado fundamentalmente en la topografía y las murallas. Como es obvio, consideraremos todos los elementos constructivos (casas, patios, techumbres, etc.) en la valoración final.

\subsection{Visibilidad en el interior del poblado (entre el R1 y el R2)}

En este apartado analizamos la visibilidad potencial entre los recintos interiores del oppidum: el superior o "croa" (R1) y el habitacional (R2) concéntrico al anterior. El R1 sería un espacio, aun sin amurallar (unwalled), con un dominio visual generalizado sobre el espacio que ocupa el R2 (Fig. 3). Solo quedarían excluidos los sectores más alejados y situados al $\mathrm{S}$ y, en menor medida, los situados al NNE. En todo caso hay muchas interrupciones en la visibilidad, en parte por efecto de la topografía actual, que integra estructuras arqueológicas excavadas y enterradas.

La construcción de la muralla modificaría las posibilidades de visibilizar el R2 desde el R1. En el estado actual de la muralla, las conexiones visuales desde el R1 se concentran hacia las zonas donde está derrumbada y soterrada ( $\mathrm{N}$ y S), como se deduce de los valores más altos de visibilidad acumulada, siempre situados hacia estas zonas. Más allá de lo anterior y en su estado actual (present walls), solo se puede superar la muralla como barrera visual desde zonas puntuales muy próximas o a través de la puerta. Si elevamos la mura1la $(75 \mathrm{~cm})$, estos puntos desaparecen y las escasas posibilidades de observación del R2 se sitúan en el derrumbe de la muralla. Incrementando $150 \mathrm{~cm}$ a la altura de la muralla, el panorama ya no cambia. Toda posibilidad de observación prácticamente se limita a los hilos visuales que, a través de la puerta $\mathrm{E}$, se establecen sobre algún punto de la ronda superior en torno al recinto central. A partir de $+150 \mathrm{~cm}$, la posibilidad de visibilizar cualquier construcción del recinto habitacional (R2) es casi nula, en especial por el E y el O, ya que las posibilidades de visibilizar parte de estas construcciones, con alturas entre 1 y $5 \mathrm{~m}$, se reducen en la práctica a las localizadas en la ronda superior, un espacio caracterizado, precisamente, por la ausencia de estructuras en altura (Anexo AC4, AC5 y AC6). Más allá de este espacio cualquier posibilidad de lograrlo pasaría porque las construcciones superaran como mínimo los $7 \mathrm{~m}$, lo cual es muy improbable.

El R1 es un espacio que no sería visible desde la totalidad del R2, aún antes de haber sido amurallado (unwalled) (Fig. 4). El R1 es casi invisible desde el $\mathrm{O}$, y deja de serlo en las demás direcciones a medida 

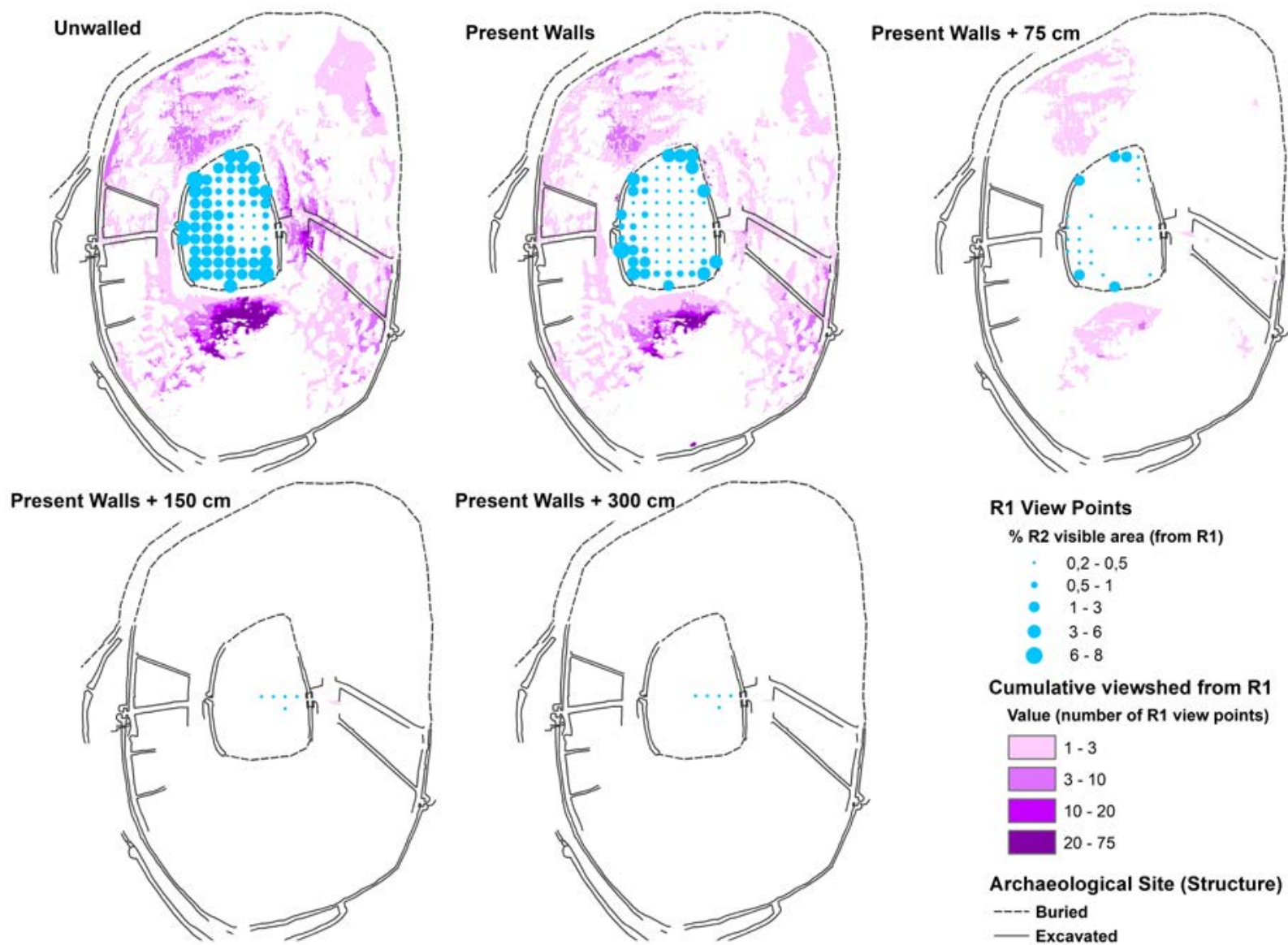

Cumulative viewshed from R1 Value (number of R1 view points)

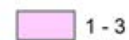

$3-10$

$10-20$

$20-75$

Archaeological Site (Structure) ---- Buried

Excavated

Fig. 3. Simulación de la visibilidad desde el R1 hacia el R2 con cinco alturas de muralla (unwalled, present walls, $+75,+150,+300 \mathrm{~cm}$ ). El tamaño de los puntos de muestreo representa el porcentaje de superficie visible del R2. En el R2 aparece la visibilidad acumulada calculada desde los puntos anteriores. En color en la edición electrónica.

que nos alejamos (sectores E, NO y SE). El R1 es muy vulnerable visualmente desde el $\mathrm{S}$, y menos desde el E hacia donde se orienta, topográficamente, como un plano inclinado. La construcción de la muralla configura un espacio infranqueable visualmente desde el R2. En la actualidad (present walls) solamente es visible desde los sectores donde la muralla está totalmente derrumbada ( $\mathrm{N}$ y S). Desde ellos, aumentando apenas la altura de la muralla conservada, las conexiones visuales únicamente se mantienen a través de las puertas.

\subsection{Visibilidad desde el poblado hacia su entorno (desde el R1 y el R2 hacia el E)}

En este apartado analizamos los resultados de los análisis de visibilidad desde los distintos espacios in- teriores del poblado (R1y R2) hacia el exterior del oppidum. Para ello haremos referencia a distintas distancias de su entorno inmediato. La construcción de la muralla que rodea el R1 supone su aislamiento perceptivo, que se produce, en cualquier caso, respecto al entorno más próximo del oppidum. Antes de la construcción de la muralla, gran parte de ese entorno era visible desde la croa (R1). En un escenario con murallas algo más altas que las actuales, el R1 no tendría visibilidad sobre ningún punto del entorno, exceptuado zonas muy lejanas en dirección E.

Para valorar con más detalle la visibilidad desde el R2 sobre su entorno inmediato hemos dividido ese espacio (E200) en 4 anillos: 0-50 m, 50-100 m, 100$150 \mathrm{~m}$ y 150-200 m (Anexo AC7). Con ello pretendemos analizar cómo varía la percepción del entorno con la distancia y respecto a la altura de la muralla. El emplazamiento del R2 permite una visibilidad general 

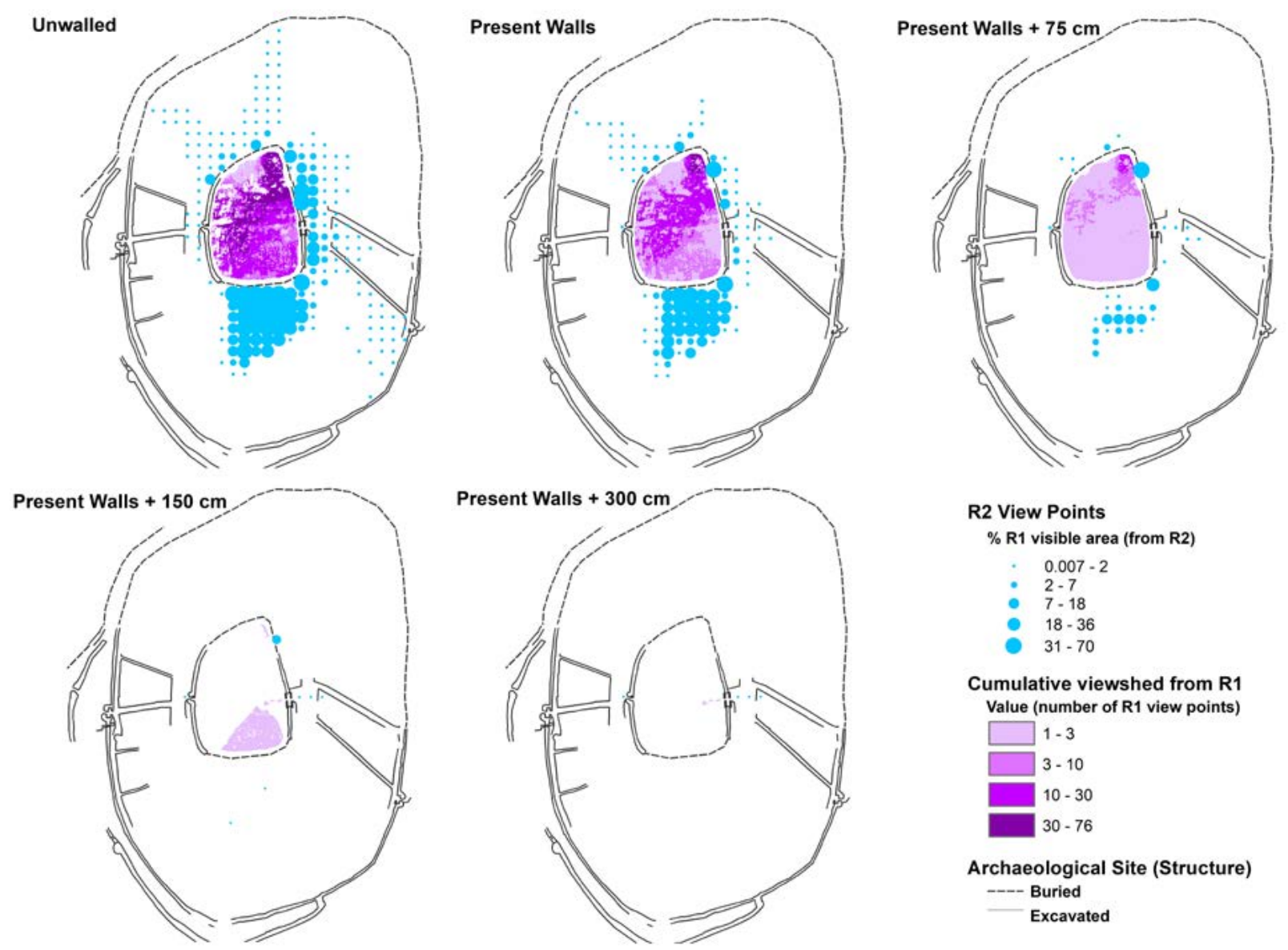

Cumulative viewshed from R1

Value (number of R1 view points)

$\square-3$

ए $3-10$

$10-30$

$30-76$

Archaeological Site (Structure)

---- Buried

Excavated

Fig. 4. Simulación de la visibilidad desde el R2 hacia el R1 con cinco alturas de muralla (unwalled, present walls, $+75,+150,+300 \mathrm{~cm}$ ) del oppidum de San Cibrán de Las. El tamaño de los puntos de muestreo representa el porcentaje de superficie visible del R1. En el R1 aparece la visibilidad acumulada calculada desde los puntos anteriores. En color en la edición electrónica.

sobre su entorno inmediato (E200) desde todos los sectores, aunque destaca, especialmente, el sector $\mathrm{O}$, y en menor medida el $\mathrm{N}$ (anillos 100-150 y $150-200$ m) o el E (anillo 50-100 m). El sector SE es el que ofrece una visibilidad menos destacada sobre su entorno. La incidencia de las murallas sobre el panorama anterior es clara al modificar las posibilidades perceptivas previas a su construcción. Esta modificación es más evidente en el entorno más próximo con menos altura de muralla, ya que en el entorno más alejado los cambios perceptivos dramáticos ocurren con alturas mayores. Por ejemplo, la visibilidad desde cualquier sector sería residual alzando $75 \mathrm{~cm}$ la muralla en el primer anillo de distancia $(0-50 \mathrm{~m})$. Para que eso ocurra en el tercero (100-150), necesitaríamos aumentar su altura $300 \mathrm{~cm}$. Con alturas inferiores los cambios más dramáticos se sitúan en los sectores del R2 más próximos a la muralla, que quedan visualmente aisla- dos del exterior. En otros puntos más alejados de las murallas disminuiría la proporción de superficie visible de una forma menos extrema (Anexo AC8).

\subsection{Visibilidad desde el entorno hacia el poblado (desde el E hacia el R1 y el R2)}

En este apartado analizamos los resultados de los análisis de visibilidad desde el entorno del poblado hacia los espacios interiores: la "croa" (R1) y el recinto habitacional (R2). El R1 es, aun sin amurallar, un espacio prácticamente oculto desde su entorno inmediato $(200 \mathrm{~m})$ (Fig. 5). Tendríamos que alejarnos más de $700 \mathrm{~m}$ para localizar algunos puntos con una visibilidad efectiva sobre el recinto, y casi $800 \mathrm{~m}$ para que cubriera más del $8 \%$. Prácticamente en el entorno de $875 \mathrm{~m}$ de este recinto ningún punto tiene 
visibilidad sobre él, salvo visibilidades puntuales de pequeñas zonas que se aprecian por el desmantelamiento de las murallas (sector $\mathrm{N}$ y S del recinto) o a través de la apertura de las puertas. La construcción de la muralla reafirma y consolida la invisibilidad del recinto desde un entorno ampliado. La exposición visual del recinto queda reducida a posiciones elevadas del entorno como el castro de San Trocado (al S) o los altos del NE, desde donde se vería de forma parcial $(+75,+150 \mathrm{~cm})$ o residual $(+300)$-menos del $3 \%$ del interior del recinto-. Además, la distancia desde esas posiciones, situadas a más de un kilómetro, no posibilitaría la percepción de rasgos individuales. A esa distancia solamente sería posible detectar, en ciertas condiciones, a seres humanos como puntos en movimiento en R1 (Fábrega-Álvarez y Parcero-Oubiña 2019).
Sin amurallar, el R2 es un espacio expuesto visualmente desde su entorno inmediato (E200), en especial por el O (Anexo AC9), y esta exposición, en términos de superficie visible, es aun mayor desde zonas más alejadas (Fig. 6). En cualquier caso, el R2 es un espacio más expuesto desde su entorno que el R1. A medida que incrementamos la altura de las murallas, esa exposición se ve reducida en diferentes zonas. Resulta especialmente significativa en el entorno de $200 \mathrm{~m}$ a partir de una altura de murallas de $+150 \mathrm{~cm} \mathrm{o}+300 \mathrm{~cm}$, escenarios en donde la visibilidad desde ese entorno sobre el R2 sería residual. Hay que señalar que con una altura de muralla de $+300 \mathrm{~cm}$, la ocultación del recinto desde el entorno se ampliaría notablemente, especialmente, por el SO.
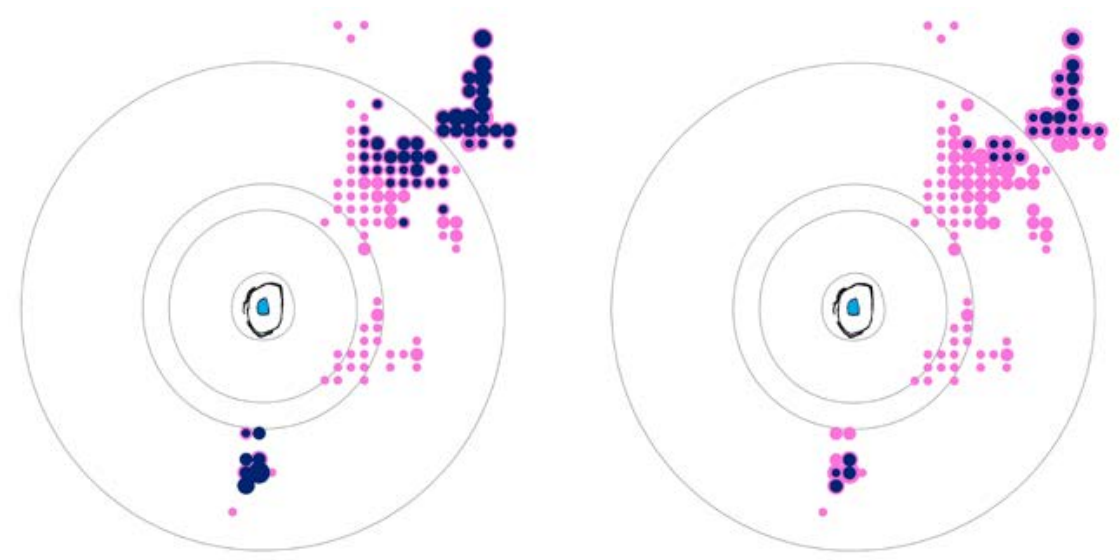

Present Walls / Unwalled

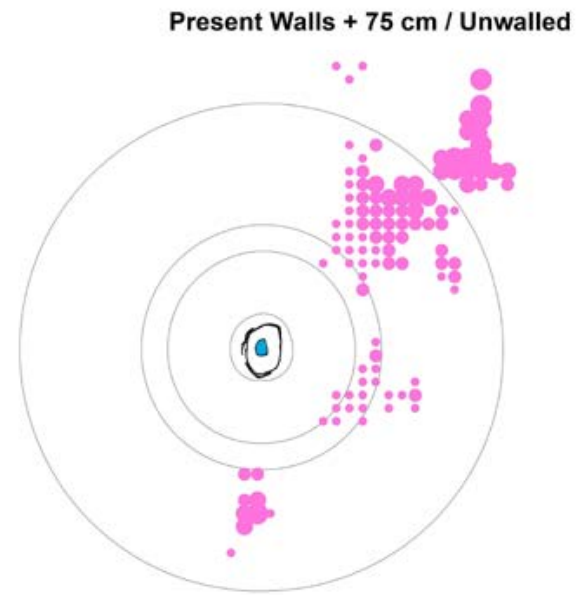

Effective visibility (to R1)

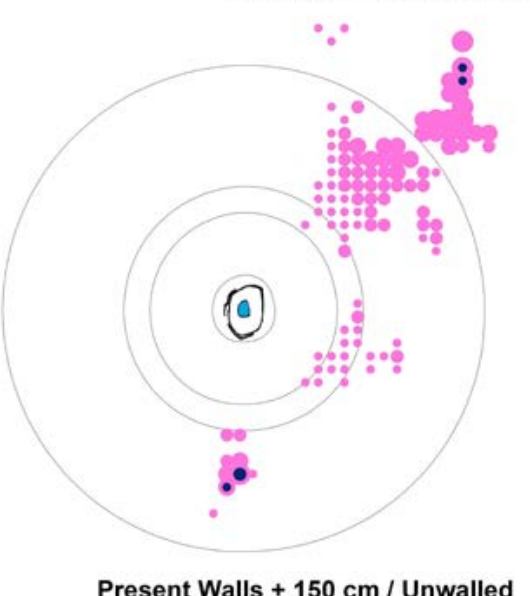

Present Walls $+300 \mathrm{~cm} /$ Unwalled

Fig. 5. Simulación de la visibilidad efectiva desde el entorno hacia el R1 con distintas alturas de muralla. El tamaño de los puntos de muestreo representa el porcentaje de superficie visible del R1. Comparativa del porcentaje visible del sitio sin amurallar (unwalled) con diferentes alturas de muralla (present walls, $+75,+150,+300 \mathrm{~cm}$ ). Radios de referencia de 200, 675, 875 y $2000 \mathrm{~m}$. En color en la edición electrónica. 

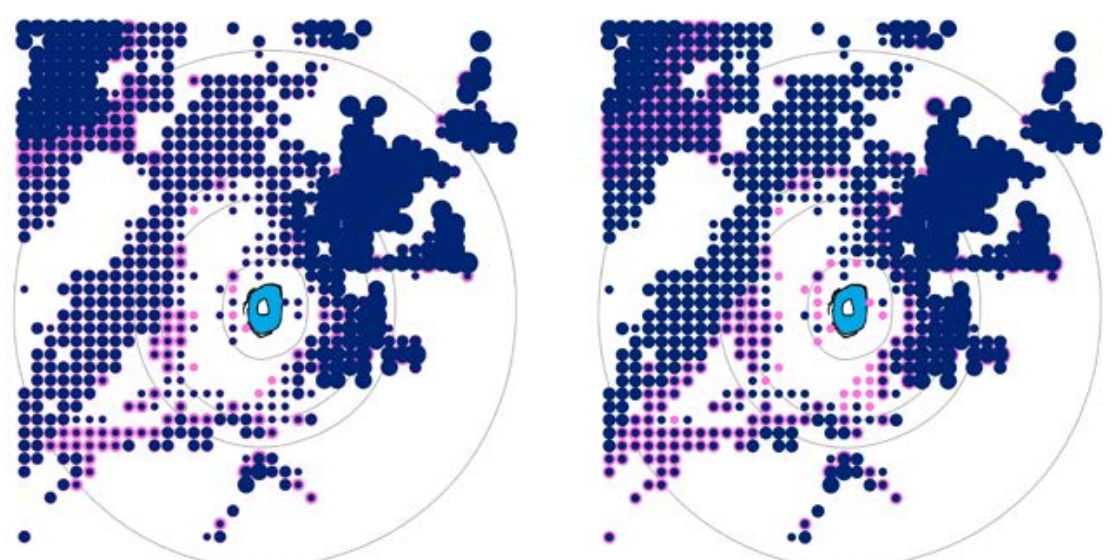

Present Walls / Unwalled
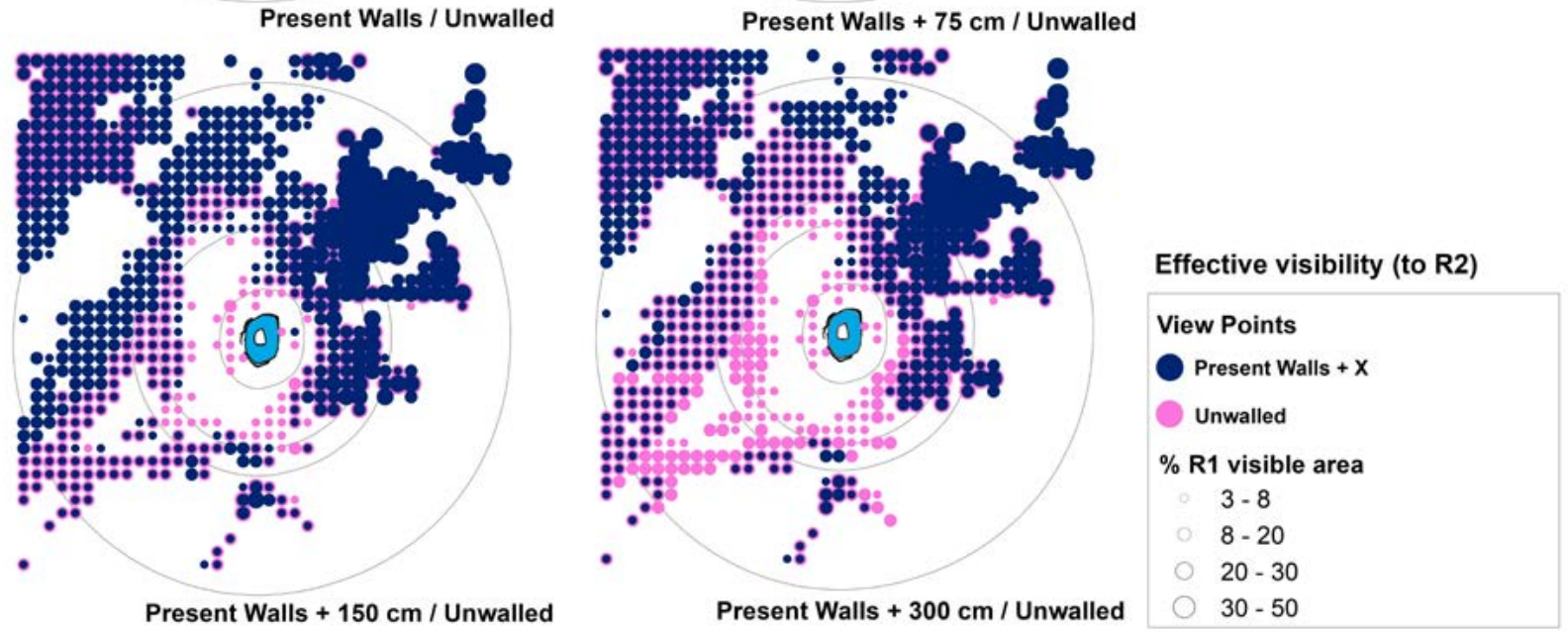

Fig. 6. Simulación de la visibilidad efectiva desde el entorno del oppidum de San Cibrán de Las hacia el R2 con distintas alturas de muralla. El tamaño de los puntos de muestreo representa el porcentaje de superficie visible del R2. Comparativa de porcentaje visible del sitio sin amurallar (unwalled) con diferentes alturas de muralla (present walls, $+75,+150,+300 \mathrm{~cm}$ ). Radios de referencia de 200, 675, 875 y 2000 m. En color en la edición electrónica.

\subsection{Las puertas: visibilidad $y$ acceso entre los espacios $(E, R 1, R 2)$}

En este apartado caracterizaremos en términos perceptivos, los accesos a los distintos recintos a través de las puertas de la muralla. El siguiente análisis es válido en ambos sentidos; es decir, se puede interpretar tanto para entrar como para salir de cada espacio, si bien la narrativa se centra en un sola dirección, bien para simplificar, bien para enfatizar su sentido. Dicho análisis es complementario con el que venimos manejando anteriormente, que pretendía valorar la incertidumbre de la altura de las murallas y su efecto en la percepción visual. Por tanto, lo que pretendemos ahora es valorar la incidencia perceptiva de los accesos y las calles, partiendo de las murallas y muros que delimitan los bloques de unidades familiares como barreras visuales infranqueables (Fig. 7). En este sentido no deja de ser parte de la estrategia de simulación, basándonos en la consideración previa de que la altura original de estos elementos (murallas y muros) sería suficiente para bloquear la visión. Lo anterior, especialmente en el caso de los muros de los bloques de las unidades familiares, no es un hecho contrastado ni asumido en la investigación, sino un planteamiento para evaluar la percepción visual con independencia de la incertidumbre sobre la altura de estos elementos. Dicho lo anterior, y teniendo en cuenta que muchos de estos muros son parte de una vivienda, granero u otra construcción techada, parece razonable plantear que tendrían una altura más que suficiente para bloquear la visión, especialmente desde la localizaciones que manejamos a continuación. 
La estructura del poblado pone en juego varios elementos que dificultan enormemente la visibilidad entre los diferentes espacios que delimitan las murallas, a través de los vanos de sus puertas. Estos elementos son los siguientes (Figs. 7 y 8): en primer lugar, la anchura de la muralla, reforzada siempre en las puertas con diferentes estructuras (torreones, puestos de guardia, etc.), lo cual alarga el vano convirtiéndolo en un corredor cuya orientación define lo que es visible y lo que no. En segundo lugar, la estructura de las vías de acceso al poblado y de su interior, que no se alinean con la orientación de los vanos, lo cual dificulta la percepción del interior del poblado. En tercer lugar, las puertas, que no son sucesivas; es decir, no están situadas a la menor distancia posible una de otra. Esta lógica de estructuración de los accesos no contradice otras interpretaciones, como por ejemplo la que relaciona la orientación de la puerta $\mathrm{O}$ de la croa con el ocaso del sol en el solsticio de verano (Álvarez et al. 2017b: 231). Si bien hay que decir que esa interpretación solamente explica una de las puertas, mientras nuestra lógica explica todas las puertas del poblado.

Estas características de las entradas configuran una lógica de acceso como la que describimos a continuación (Figs. 7 y 8): el acceso desde la puerta $\mathrm{E}$ al poblado se haría prácticamente a ciegas, si tenemos en
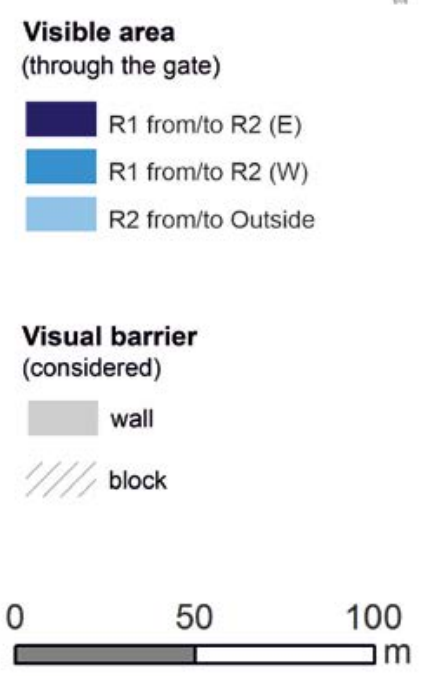

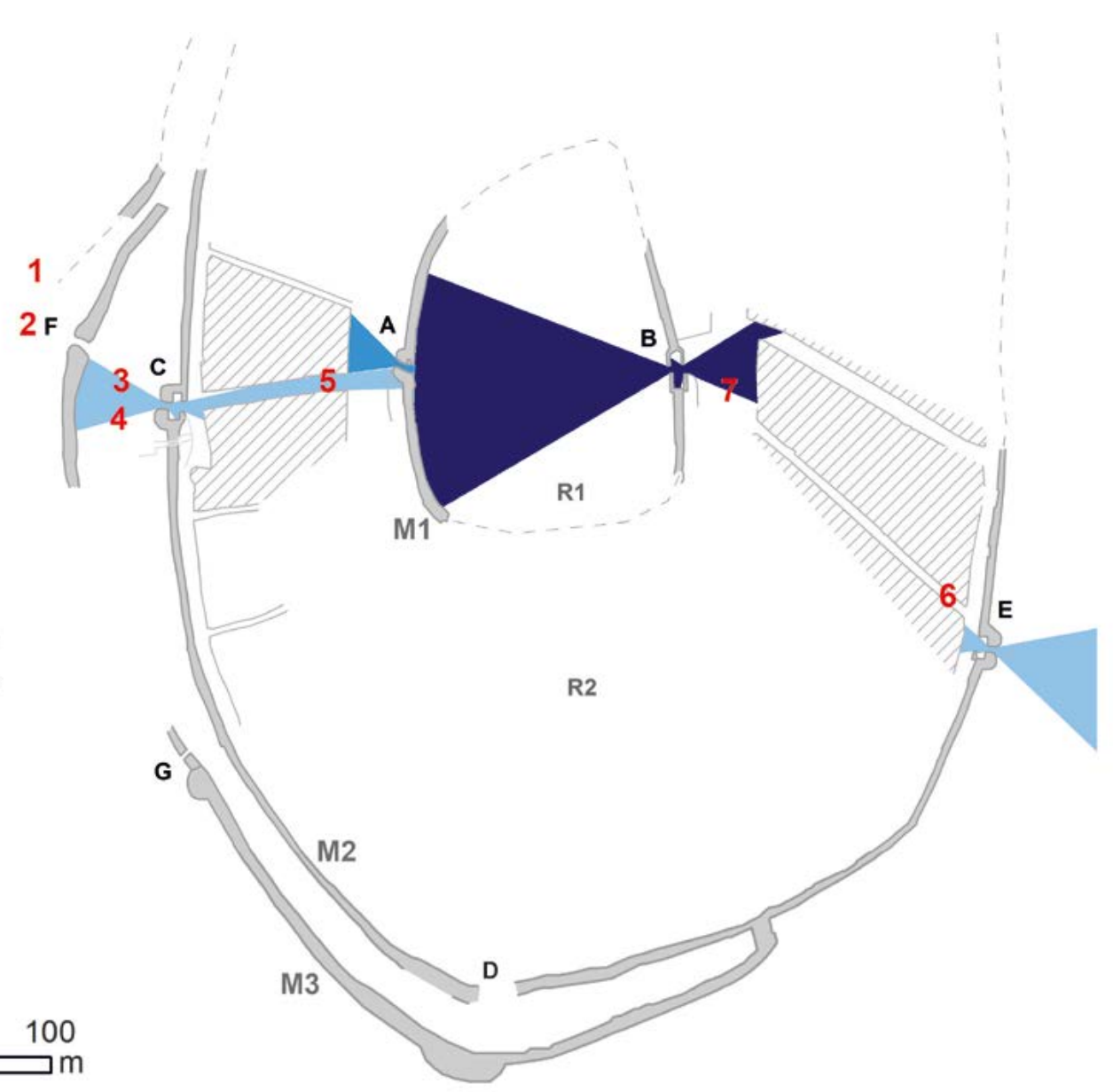

Fig. 7. Representación de la visibilidad a través de los vanos de las puertas entre el R1 y el R2. Las zonas señaladas representan los espacios de cada recinto desde donde es posible visibilizar el interior del otro a través de los vanos de las puertas, considerando la muralla (wall) y los espacios cerrados habitacionales (block) como barreras visuales infranqueables. La estructura del oppidum revela un alto grado de impermeabilidad visual, manifiesta por la imposibilidad de observar desde el entorno el espacio interior por el acceso principal situado al oeste. Sin atravesar la puerta $\mathrm{F}$ no es posible ver el interior del R2, visible solo desde la inmediatez de la puerta $\mathrm{C}$ y desde el interior del espacio entre las murallas (M2 y M3). Además, desde ningún punto de ese espacio entre las murallas es posible observar el interior del R1, que solamente es visible desde la ronda superior del R2 tanto por la puerta oeste (A) como por la puerta este (B). La figura también posibilita una lectura inversa, aunque con matices, es decir, las zonas desde las que hay visibilidad desde el interior de los recintos hacia el exterior del poblado a través de los vanos de las puertas. En color en la edición electrónica. 


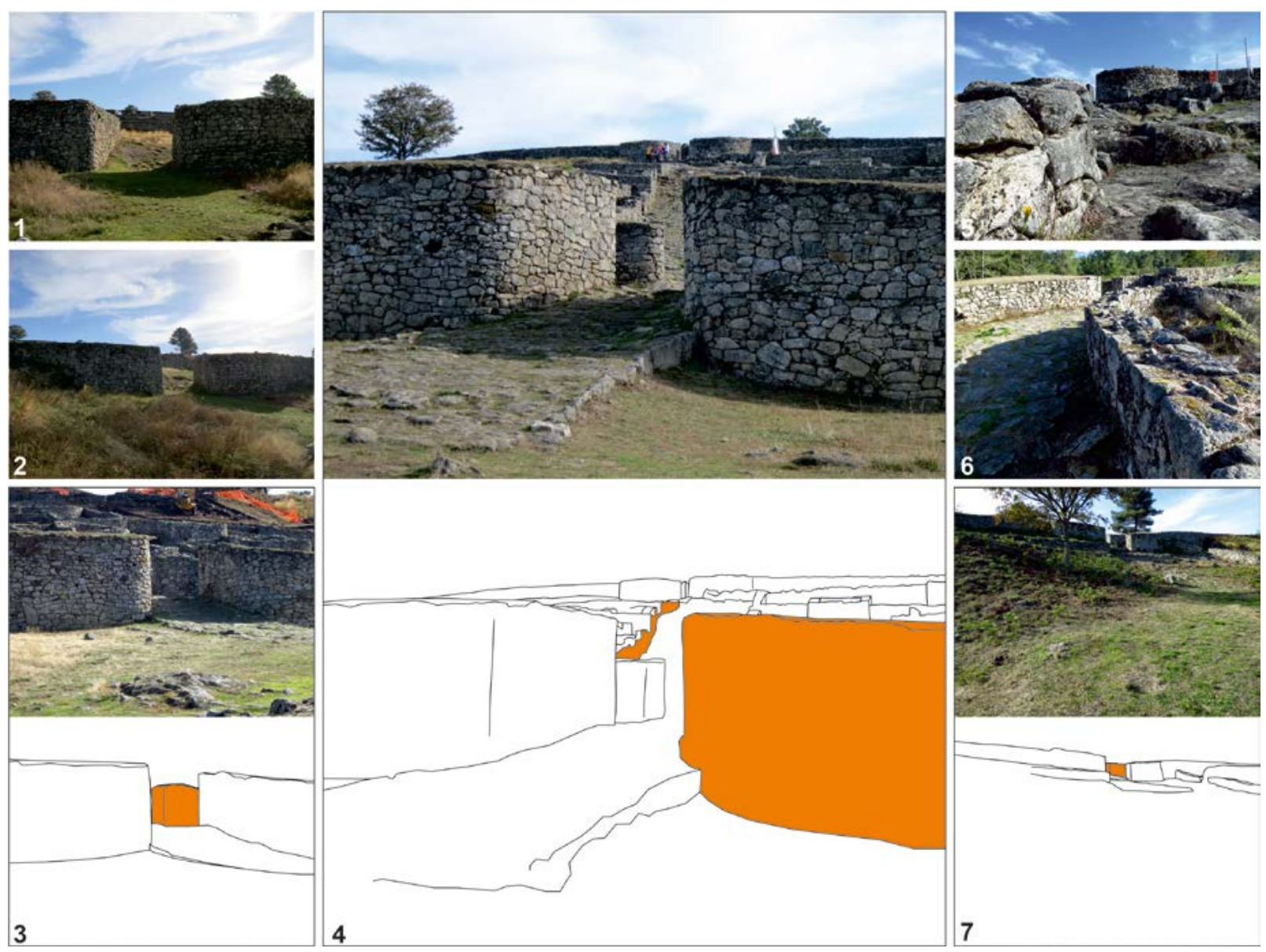

Fig. 8. Representación de la visibilidad del oppidum de San Cibrán de Las a través de los vanos de las puertas. Las fotografías y las puertas se localizan en la figura 7. Las fotos 1 y 2 documentan la visibilidad desde la inmediatez de la puerta $\mathrm{F}$ hacia el interior. En la foto 2 puede verse la puerta $\mathrm{C}$, pero no el interior del R2 debido al muro interior del cuerpo de guardia que actúa como barrera. La foto 3 muestra la visibilidad desde la inmediatez de la puerta $\mathrm{C}$, el detalle del cierre de la proyección visual logrado a partir del muro interior del cuerpo de guardia (destacado en el dibujo) mencionado en la foto 2 . La foto 4 deja patente la visibilidad desde la proximidad de la puerta C. La proyección en altura del torreón (destacado en el dibujo) y de la esquina superior de la unidad doméstica situada en la ronda superior (señalada en el dibujo) cerrarían la visual sobre la puerta A, situada al fondo, desde cualquier punto de la calzada de acceso a la puerta (C). En la foto 5 se advierte la relación visual entre el esquinal (en foto 4) y la puerta A. La foto 6 refleja la relación visual con la puerta E desde el interior del poblado. Nótese que no hay visibilidad desde la calle principal hacia el exterior del mismo, si proyectamos el muro que delimita las unidades domésticas. La foto 7 muestra la visibilidad desde el límite de apertura visual de R1 a partir del vano de la puerta B. De nuevo el muro interior del cuerpo de guardia (destacado en el dibujo) impide la visibilidad del interior del R1. En color en la edición electrónica.

cuenta que el espacio visible desde la puerta se reduce a un pequeño espacio de la ronda inferior. Las calles principales que dan acceso a la ronda superior no están alineadas con la dirección del vano de esa puerta. Esta configuración se repite en las puertas de acceso al recinto superior (R1). Aquí, la visibilidad a través del vano de la puerta queda reducida al espacio inmediato de la ronda superior, lo cual, parece lograrse, con la misma estrategia arquitectónica; desalinear la puerta y dirección del vano con las calles que comunican ambas rondas (R1 y R2). El acceso desde el entorno al interior del poblado (R2) por el O impedi- ría, aun con las puertas abiertas, la visibilidad del poblado desde la entrada principal de este recinto, o el exterior desde el poblado en sentido inverso. Como vemos en las figuras 7 y 8 , el ángulo y longitud de los vanos es suficiente para impedir la visibilidad entre los espacios (R2 y E) a través de las puertas principales. El espacio de acceso conformado entre las murallas (M2 y M3 en la Fig. 7), las características y ubicación de las diferentes puertas (C, D, F y G en la Fig. 7) confieren a este sistema varias posibilidades de accesibilidad y percepción entre el exterior e interior del poblado. Dicho espacio podría haber funcionado 
como un sistema de control, regulando el acceso de los individuos a partir de distintas posibilidades que otorgan las 4 puertas que presenta, 2 en cada una de las murallas. Este espacio es ciego, ya que una vez dentro las murallas que lo flanquean no permiten ver ni el interior del poblado ni el entorno, quedando la visibilidad reducida a dicho espacio. En definitiva, este sistema de acceso posibilitaría realizar la entrada o salida del poblado a partir de diferentes recorridos que representan distintas condiciones de acceso, percepción y control. Estas condiciones que denominamos como fast glory (gloria rápida) y checked access (acceso controlado) se describen a continuación. Fast glory se caracteriza por el acceso al recinto por la puerta principal (F en la Fig. 7) e, inmediatamente, al poblado a través de la puerta más monumental ( $\mathrm{C}$ en la Fig. 7). La puerta da acceso a una de las calles transversales principales con acceso directo al recinto superior (R1). Hay $30 \mathrm{~m}$ entre una y otra puerta (F y C en la Fig. 7). Este recorrido, aunque más rápido, no está exento de las restricciones perceptivas para el visitante que, como recordaremos, no percibe el interior del poblado hasta que emboca el vano de la segunda puerta ( $\mathrm{C}$ en la Fig. 7). Checked access se caracteriza por el acceso al recinto por la misma puerta ( $\mathrm{F}$ en la Fig. 7) y, una vez allí, recorriendo los más de $250 \mathrm{~m}$ que la separan de la puerta sur (D en la Fig. 7) que da acceso al poblado; pasando entre las dos grandes murallas (M2 y M3) que cerrarían un espacio ascendente que se va estrechando. En algunas zonas la distancia entre murallas es inferior a $10 \mathrm{~m}$. Un recorrido alternativo similar sería acceder a este recinto desde la puerta secundaria ( $G$ en la Fig. 7), formada por un vano en codo y estrecho separado por más de $100 \mathrm{~m}$ de la puerta sur (D en la Fig. 7). Los dos últimos recorridos conllevan cierta desorientación para un visitante novel por la falta de perspectiva visual durante un recorrido largo y en giro continuo. A la vez, el recorrido está expuesto al control ejercido desde cada una de las murallas $\mathrm{y}$ torreones sobreelevados.

\section{FUNCIÓN Y SENTIDO, OCULTACIÓN Y MONUMENTO}

A continuación haremos una serie de valoraciones que tienen en cuenta los resultados del análisis, así como las estimaciones de la altura de la muralla que proponíamos al principio. Estas valoraciones tienen en cuenta la mayor precisión y certidumbre de los resultados en el eje E-O del poblado, que como decíamos al principio, ha sido excavado en extensión y la arquitectura desnuda se refleja en el modelo digital del terreno (MDT). En este sentido las valoraciones se ajustan más, en general, en escenarios en los que la muralla alcanza, al menos, entre los $+75 \mathrm{y}+150 \mathrm{~cm}$ de altura en la primera muralla (M1) y, entre los $+150 \mathrm{y}$ $+300 \mathrm{~cm}$ en las restantes (M2 y M3); escenarios que se sostienen, habida cuenta de los máximos establecidos a partir de las proyecciones de las escaleras de acceso (Fig. 2 y Anexo Tab. A). Estas proyecciones parecen apuntar, precisamente, una tendencia a máximos mayores en la M2 y la M3 que en la M1. Como decíamos al principio, las estimaciones de sus excavadores sostienen estas alturas e incluso alturas superiores.

La lógica de San Cibrán de Las está caracterizada por una impermeabilidad perceptiva, en donde la visibilidad parece restringirse al interior de cada espacio (R1, R2, E). El acceso visual a cada uno de estos espacios no se anticipa hasta la estricta inmediatez de la puerta debido a un patrón claro de localización y construcción de los vanos. Lo anterior es, en general, válido en ambas direcciones: para los que salen y, más aun, para los que entran. Las murallas, como principal elemento arquitectónico, invierten la lógica del paisaje previo, abierto y permeable desde el punto de vista perceptivo. Esta lógica se aplica a la estructura general del sitio formada por los recintos amurallados y se refuerza más aun con la materialización de todos los elementos constructivos. Así, por ejemplo, el R2 aparece como recinto habitacional densamente edificado con barreras visuales continuas (muros, tejados, etc.) que limitarían aun más, tanto la percepción dentro del recinto, como desde cualquier otro espacio. A juzgar incluso por el análisis gamma de la estructuración espacial de las unidades domésticas del oppidum ${ }^{2}$, esta lógica de impermeabilidad perceptiva también está presente en los espacios privados. La construcción del oppidum supuso pasar de un paisaje abierto a otro compartimentado en espacios cerrados en sí mismos. La ocultación del interior del oppidum desde el entorno inmediato es muy notable para el R1 y el R2. Lo anterior limitaría, en todo caso, las posibilidades de obtener información de cierto detalle acerca de aspectos como rasgos identitarios de los individuos o prácticas sociales llevadas a cabo en el interior del poblado.

La condición de la muralla como monumento emerge, en primer lugar, del análisis de visibilidad de los recintos, en cuanto su ocultación y configuración se deben fundamentalmente a ella. En este sentido, a juzgar por su efectividad como barrera visual, las murallas alcanzarían gran proyección en el paisaje. Hasta es posible que las murallas de ambos recintos, a la vez que ponen en juego una estrategia de invisibilización del espacio interior, estén creando desde el entorno un efecto de continuidad visual que evoca la escenografía

\footnotetext{
2 X. M. Ayán Vila. "Casa, familia y comunidad de la Edad del Hierro en el NW". Tesis doctoral inédita, Universidad de Santiago de Compostela, 2011, p. 660.
} 
de un poblado inexpugnable, lograda a partir de la percepción concatenada en vertical de los lienzos de muralla. Es decir, visualmente, cuando acaba una muralla empieza la otra, proyectando verticalidad a la perspectiva (Anexo AC10). Además la monumentalidad de las murallas está reforzada con otros recursos. En primer lugar por el efecto skyline de la muralla superior (M1) desde el entorno del oppidum (ParceroOubiña 2005: 21; Bernardo y García-Quintela 2008). En segundo lugar por el criterio selectivo del material lítico y la mampostería. El granito de peor calidad se utilizó en las viviendas, mientras el de mayor calidad y tonalidad más clara se empleó en los tramos exteriores de la muralla a ambos lados de la puerta occidental (C en Figs. 1, 7 y 8) con técnicas arquitectónicas como el aparejo poligonal, inexistente en otros tramos $^{3}$. De forma análoga, en el interior del poblado, la cimentación de la cara exterior de la muralla occidental (M1) consiste en bloques pétreos de grandes dimensiones con paramento helicoidal muy cuidado en su factura (Álvarez et al. 2009: 202). La mampostería de la entrada al R1 y al R2 parece indicar que la monumentalidad de la muralla también se articula a corta distincia, como recurso complementario de la proyección de la visibilidad a kilómetros de distancia.

Pensando en San Cibrán como un espacio de comunicación determinado por el acceso efectivo y visual a los distintos espacios, surgen varias líneas interpretativas. Las diferencias en las posibilidades de percepción, comunicación o participación podrían estar relacionadas con el acceso regulado a los espacios. Esta visibilidad diferencial significa, en primera instancia, la imposibilidad de observar determinadas prácticas sociales relacionadas con un espacio y un momento determinado. Por ejemplo, si pensamos en la "croa" (R1) como un espacio cultual, cualquier práctica ritual aquí desarrollada es prácticamente imperceptible desde cualquier otro espacio. La "croa" excluye no solamente a los que están fuera del poblado, sino también a los que están en su recinto habitacional (R2). Para simplificar esquematizaremos dos posibilidades que representan diferencias claras en las limitaciones de acceso y percepción del espacio, que denominamos como total access (acceso total) y limited access (acceso limitado). Estas alternativas no presuponen limitaciones diferenciales dentro de la comunidad, sino que son meras descripciones de las posibilidades abiertas por la materialización de las estructuras del oppidum en términos de percepción visual y acceso. Total access caracteriza el acceso a lo alto de las murallas a través de sus numerosas escaleras. Supone la posibilidad de un control visual amplio, al menos de los

\footnotetext{
${ }^{3}$ Véase nota 2, p. 658
}

espacios inmediatos (interiores y exteriores) y, en cualquier caso, del entorno. El acceso a todos los recintos o la entrada y salida a través de lo que denominamos fast glory serían posibilidades alineadas con un acceso sin restricciones de ningún tipo. Limited access caracteriza la inaccesibilidad a las murallas y el acceso limitado a ciertos espacios cuyas posibilidades perceptivas quedan circunscritas a los mismos. El acceso al poblado, a través de los recorridos denominados checked access, estaría alineado con un acceso restringido y limitado.

La configuración y materialización de los recintos amurallados en San Cibrán de Las parece obedecer a la misma lógica defensiva que los castros del noroeste (Parcero-Oubiña 2013), sostenida por una mayor anchura de la muralla y acumulación de estructuras defensivas en aquellos sectores con pendientes más suaves, y por tanto más vulnerables (Anexo AC11). La imponente anchura de las murallas, el acceso a su parte superior a través de escaleras interiores y la presencia de cuerpos de guardia y torreones son elementos presentes no solamente en los recintos de acceso al poblado sino también al recinto superior. Podemos pensar que la imposición de una lógica perceptiva caracterizada por la ocultación y restricción visual de los recintos responde a una estrategia poliorcética que incluiría el recinto superior (R1) como un último reducto defensivo. Así, estos recursos pueden comprenderse dentro de una sociedad guerrera con poblados fortificados protegidos ante la amenaza exterior. Esto podría estar en consonancia con el aumento de la tensión intercomunitaria que podría haberse dado antes del siglo II a. C. con el aumento de la población y número de poblados (González-Ruibal 2006: 279-316). Sin embargo, también sería posible interpretarlos como un recurso de control interno de los espacios, con la finalidad de articular mecanismos de regulación de la diferencia, la fragmentación o la jerarquía de la población local, limitando el acceso a espacios (rituales, habitacionales, heroicos) a los que no es posible, ni siquiera, acceder visualmente desde fuera. A ese respecto señalamos como el acceso a la primera muralla (M1) es clave para superar esta lógica, en la medida que supone el acceso a la "croa" (R1), el dominio visual sobre el R1 y el R2 y otras murallas (M2 al menos), así como una amplia perspectiva del entorno. La lógica defensiva que parece presentar en origen el recinto superior (R1) no excluye su sentido cultual, sino más bien podría reafirmar la importancia de este ámbito en estas sociedades, situándolo como un espacio central, exclusivo, invisible e inaccesible desde fuera, y extremadamente protegido por sucesivas líneas de muralla. Estos mecanismos de regulación también pudieron ser articulados en consonancia con los procesos de concentración poblacional que se dieron en 
los oppida. Además de articular estrategias de cohesión comunitaria, es posible que también se recurriese a estrategias de diferenciación del poder entre grupos, a partir de la construcción de espacios, y especialmente de su acceso a través de diferentes puertas cuyos valores pudieron estar representados en la coreografía escenográfica que representa el propio recorrido.

En definitiva, esta lógica privativa basada en la limitación perceptiva de los espacios interiores y exteriores pudo ser un recurso extendido en los poblados de la II Edad del Hierro, habida cuenta de la sucesión de recintos amurallados en muchos de ellos, y de la localización y los ángulos de los vanos de las puertas. Estos recursos perceptivos en relación al dominio y el control pudieron ser materializados, tal vez por primera vez en este momento, a través de una arquitectura que tiende a la verticalidad (murallas, torreones, casas con techumbres apuntadas). Precisamente en una sociedad guerrera, esta arquitectura, parece haber abierto la posibilidad de mantener dos tipos de perspectivas que definen dos posiciones relativas al poder: los que miran desde abajo hacia arriba (sometidos) y los que miran de arriba hacia abajo (poderosos). Ambas perspectivas están definidas por la posición del individuo en una materialidad que las ampara y que, como hemos visto en San Cibrán, amplía y limita las posibilidades perceptivas del entorno. En una sociedad heroica lo anterior se refleja también en otros ámbitos como la estatuaria de los guerreros, erguidos, con la mirada al frente, y localizados, tal y como se ha sugerido (Silva 2007, 2012), en lo alto y próximos a las puertas de los poblados. En este sentido, la escultura parece haber materializado una perspectiva visual (desde arriba) que ya estaba presente en lo alto de las estructuras defensivas. De forma similar, la arquitectura obliga a adoptar una mirada sometida, desde abajo, hacia murallas y torreones que representarían el poder en ausencia de los guerreros.

\section{CONCLUSIÓN}

Las Tecnologías de Información Geográfica nos permiten obtener modelos digitales de alta resolución, en donde las estructuras arqueológicas pueden ser integradas en un entorno geográfico amplio. Esto nos posibilita abordar, por primera vez, paisajes digitales a gran escala, explorando cómo la arquitectura condiciona la percepción y la accesibilidad de los seres humanos. La posibilidad de alterar y reconstruir digitalmente la geometría de los restos materiales nos facilita valorar la materialidad arqueológica más allá de su estado actual. La simulación nos permite articular distintas estrategias para comprender cómo la alteración geométrica de estos restos materiales puede condicionar aspectos como la visibilidad o la accesibilidad en el paisaje.

\section{AGRADECIMIENTOS}

Yolanda Álvarez, Luis López y Miguel A. López me dieron valiosa información sobre el yacimiento, fruto de una dilata experiencia en la excavación y conservación del castro de San Cibrán de Las. También agradezco a mis compañeros, Iñaki Villa y Jorge Canosa, su dedicación en el trabajo de campo, así como a Anxo Rodríguez Paz su ayuda con las figuras. Todo el personal del Parque Arqueolóxico da Cultura Castrexa (PACC) facilitó nuestra labor.

\section{ANEXO}

En la edición electrónica de este artículo, disponible en libre acceso en la página web de la revista, se incluye un archivo que contiene el texto "Calidad de respuesta del MDT", la Tab. A y las figuras AC1-AC11.

\section{BIBLIOGRAFÍA}

Álvarez González, Y. 2009: "Escavación e consolidación arqueolóxica no castro de San Cibrao de Las, San Amaro-Punxín (Ourense)". En P. Varela Campos (ed.): Actuación Arqueolóxicas, 2008. Consellería de Cultura e Turismo, Dirección Xeral de Patrimonio Cultural. Santiago de Compostela: 72-73.

Álvarez González, Y. 2020: El poblamiento castreño en la cuenca media del Miño: una revisión diacrónica y territorial en la cuenca del Barbantiño. Tesis, E-Prints Complutense, Facultad de Geografia e Historia https://eprints.ucm.es/56481/

Álvarez González, Y.; López González, L. F.; Fernández-Götz M. y García Quintela, M. V. 2017a: "Reconsidering urbanisation in Late Iron Age Iberia: The oppidum of San Cibrán de Las (Galicia, Spain)". Prähistorische Zeitschrift 92 (2): 354-369.

Álvarez González, Y.; López González, L. F.; Fernández-Götz, M. y García Quintela, M. V. 2017b: "El oppidum de San Cibrán de Las y el papel de la religión en los procesos de centralización en la Edad del Hierro". Cuadernos de Prehistoria y Arqueología de la Universidad Auitónoma de Madrid 43: 217-239.

Álvarez González, Y.; López González, L. F. y López Marcos, M. A. 2009: "La ocupación del espacio común y privado en la citania de San Cibrán de Lás”. Revista Aquae Flaviae 41: 195-208.

Ariza, F. J.; Pinilla, C.; López, R. y Caridad, J. M. 2001: "Uso de la simulación en cartografía: conceptos básicos y aplicaciones". Mapping 71: 54-75.

Barceló, J. A. 2012: "Computer simulation in archaeology. Art, science or nightmare?". Virtual Archaeological Review 3 (5): 8-12.

Bernardo Stempel, P. de y García Quintela, M. V. 2008: "Población trilingüe y divinidades del castro de Lansbriga (NO de España)". Madrider Mitteilungen 49: 254-90.

Brandt, R.; Groenewoudt, B. J. y Kvamme, K. L. 1992: “An experiment in archaeological site location: modelling in the Netherlands using GIS techniques". World Archaeology 24: 268-282.

Branting, S.; Wu, Y.; Srikrishnan, R. y Altaweel, M. R. 2007: "SHULGI: A geospatial tool for modeling human movement and interaction". En Proceedings of the Agent 2007 Conference: on Complex Interaction and Social Emergence (Chicago): 475-487. Chicago. 
Chamoso Lamas, M. 1954: "Excavaciones arqueológicas en San Cibrán de Lás (Orense). Cuadernos de Estudios Gallegos 9: 406-410. Criado-Boado, F. 2012: Arqueológicas: La razón perdida. Bellaterra. Barcelona.

Fábrega-Álvarez, P. 2004: Poblamiento y territorio de la cultura castreña en la comarca de Ortegal. CAPA: cadernos de arqueoloxía e patrimonio 19, Universidad de Santiago de Compostela. Santiago de Compostela.

Fábrega-Álvarez, P. 2017: Recorriendo y observando paisajes digitales Una aproximación al análisis arqueológico con tecnologías de la información geográfica (TIG). Col. Tesis, Repositorio Institucional de Producción Científica (RUJA), Universidad de Jaén. Jaén. http:/hdl.handle.net/10953/1007

Fábrega-Álvarez, P. y Parcero-Oubiña, C. 2019: "Now you see me. An assessment of the visual recognition and control of individuals in archaeological landscapes". Journal of Archaeological Science 104: 56-74

Fariña Busto, F. y Fernández Bal, M. L. 1989: A "Cidade” de San Cibrán de Lás (San Amaro-Punxín, Ourense). Arqueología/Informes de la campaña 1987. Xunta de Galicia. Santiago de Compostela.

García Quintela, M. V.; González García, A. C. y Seoane-Veiga, Y. 2014: "De los solsticios en los castros a los santos cristianos: la creación del paisaje cristiano en Galicia". Madrider Mitteilungen 55: 443-485.

Gilbert, N. 2008: Agent-Based Models. Quantitative Applications in the Social Science 153, Sage. Londres.

Gillings, M.; Mattingly, D. y van Dalen, J. (eds.) 1999: Geographical information systems and landscape archaeology. The Archaeology of Mediterranean Landscapes 3, Oxbow Books. Oxford.

González-Ruibal, A. 2006: Poder y comunidad en el Noroeste de la Península Ibérica (1200 a. C. - 50 d. C.). Brigantium 18 y 19, Museu Arqueolóxico e Histórico da Coruña. La Coruña.

Grau Mira, I. (ed.) 2006: La aplicación de los SIG en la arqueología del paisaje. Universidad de Alicante. Alicante.

Hatzinikolaou, E.; Hatzichristos, T.; Siolas, A. y Mantzourani, E. 2003: "Predicting archaeological site locations using GIS and Fuzzy Logic". En M. Doerr y A. Sarris (eds.): CAA2002 The Digital Heritage of Archaeology. Proceedings of the $30^{\text {th }}$ Conference (Heraklion, Crete 2002): 169-177. Atenas.

Hodder, I. 1978: Simulation Studies in Archaeology. Cambridge University Press. Cambridge.

Lake, M. W. 2000: "MAGICAL computer simulation of Mesolithic foraging". En T. A. Kohler y G. J. Gumerman (eds.): Dynamics in human and primate societies: Agent-Based modelling of social and spatial processes. Oxford University Press. New York.

Lake, M. W. 2014. "Trends in archaeological simulation". Journal of Archaeological Method and Theory 21: 258-287.

Latour, B. 2005: Reassembling the social: An introduction to ActorNetwork-Theory. University Press. Oxford.

Lock, G. (ed.) 2000: Beyond the map: archaeology and spatial technologies. IOS Press. Amsterdam.
López Cuevillas, F. 1925: "A citania do monte A Cidade en San Ciprián das Lás”. Boletín de la Real Academia Gallega XIV: 201-206, $227-$ 232, 250-257, 301-305.

López González, L. F.; López Marcos, A. y Álvarez González, Y. 2004: "Definición y recuperación de estructuras en el castro de San Cibrán de Lás”. Cuadernos de Estudios Gallegos 117: 79-113.

Malafouris, L. 2008: “At the Potter's wheel: An argument for material agency”. En C. Knappett y L. Malafouris: Material Agency: Towards a non-anthropocentric perspective. Springer. Nueva York: 19-36.

Mayoral Herrera, V. y Celestino Pérez, S. (eds.) 2011: "Tecnologías de información geográfica y análisis arqueológico del territorio". Actas del $V$ Simposio Internacional de Arqueología de Mérida (Mérida 2007). Anejos del Archivo Español de Arqueología LIX, Instituto de Arqueología-Mérida, CSIC-Junta de Extremadura. Mérida: 411-423.

Mayoral Herrera, V.; Parcero-Oubiña, C. y Fábrega-Álvarez, P. 2017: Archaeology and geomatics. Harvesting 10 years of training in the Iberian Peninsula (2006-2015). Sidestone Press. Amsterdam.

Parcero-Oubiña, C. 2005: "Variaciones en la función y el sentido de la fortificación a lo largo de la Edad del Hierro en el NO de la Península Ibérica". En A. Blanco, C. Cancelo y A. Esparza Arroyo (eds.): Bronce Final y Edad del Hierro en la Península Ibérica. Encuentro de jóvenes investigadores. Aquilafuente 86, Fundación Duques de Soria y Ediciones de la Universidad de Salamanca. Salamanca: 11-33.

Parcero-Oubiña, C. 2013: "Midiendo decisiones locacionales. Una aproximación a la evaluación de la defensibilidad efectiva de sitios arqueológicos fortificados". Comechingonia Revista de Arqueología 17 (2): $57-82$

Pérez Outeiriño, B. 1987: “A Cidade de San Cibrán de Lás. Obxectivos e resultados das últimas intervenmcións arqueolóxicas". Lucerna 2 : $15-39$.

Sabloff, J. A. (ed.) 1981: Simulations in archaeology. University of New Mexico Press. Albuquerque.

Shannon, R. y Johannes, J. D. 1976: "Systems simulation: the art and science". IEE Transaction on Systems, Man and Cybernetics 6 (10): 723-724.

Silva, A. C. F. da 2007: A Cultura Castreja no noroeste de Portugal. Câmara Municipal de Paços de Ferreira. Paços de Ferreira.

Silva, A. C. F. da 2012: Os senhores da guerra. Câmara Municipal de Boticas. Boticas.

Stancic, Z. y Veljanovski, T. 2000: "Understanding Roman settlement patterns through multivariate statistics and predictive modelling". En G. Lock (ed.): Beyond the map: archaeology and spatial technologies. IOS Press. Amsterdam: 147-56.

Wurzer, G.; Kowarik, K. y Reschreiter, H. (eds.) 2015: Agent-Based modelling and simulation in archaeology. Advance in geographic information science. Springer-Verlag. Berlin.

Zubrow, E. 1997: "Clusters of death, pockets of survival: dynamic modeling and GIS”. En S. E. Van del Leeuw y J. McGlade (eds.): Time, process and structured transformation in archaeology. Routledge. London: 216-253. 